\title{
Diagnostics of phonological lexical processing: Pseudohomophone naming advantages, disadvantages, and base-word frequency effects
}

\author{
RON BOROWSKY and WILLIAM J. OWEN \\ University of Saskatchewan, Saskatoon, Saskatchewan, Canada \\ and \\ MICHAEL E. J. MASSON \\ University of Victoria, Victoria, British Columbia, Canada
}

\begin{abstract}
Phonological lexical access has been investigated by examining both a pseudohomophone (e.g., brane) base-word frequency effect and a pseudohomophone advantage over pronounceable nonwords (e.g., frane) in a single mixed block of naming trials. With a new set of pseudohomophones and nonwords presented in a mixed block, we replicated the standard finding in the naming literature: no reliable base-word frequency effect, and a pseudohomophone advantage. However, for this and two of three other sets of stimuli-those of McCann and Besner (1987), Seidenberg, Petersen, MacDonald, and Plaut (1996), and Herdman, LeFevre, and Greenham (1996), respectively-reliable effects of base-word frequency on pseudohomophone naming latency were found when pseudohomophones were presented in pure blocks prior to nonwords. Three of the four stimulus sets tested produced a pseudohomophone naming disadvantage when pseudohomophones were presented prior to nonwords. When nonwords were presented first, these effects were diminished. A strategy-based scaling account of the data is argued to provide a better explanation of the data than is the criterion-homogenization theory (Lupker, Brown, \& Colombo, 1997).
\end{abstract}

When reading an alphabetic script, such as English, there are two main approaches for computing a word's phonology (sound) from its orthography (print) that depend on the nature of the letter string (see Borowsky, Owen, \& Fonos, 1999, for a review). If presented with a novel orthographic pattern, some form of phonetic decoding process is likely to drive identification through the translation of individual (or small groups of) letters into their corresponding sounds. When the sound pattern is familiar to the reader, this process can also result in the activation of a memory representation of the word's sound (i.e., phonological lexical access). If presented with a word that has been encountered frequently before in print, some form of sight vocabulary process is likely to drive identification through a memory representation for the word's orthographic pattern (i.e., orthographic lexical access resulting in phonologicallexical access), a process that may also be mediated by semantic (meaning) access.

In the present study, we were concerned with experimental effects that are diagnostic of phonologicallexical access

R.B. and W.J.O. contributed equally to this manuscript. This research was supported by the Natural Sciences and Engineering Research Council of Canada in the form of grants to R.B. and M.E.J.M. and a postgraduate scholarship to W.J.O. The authors thank Jay Rueckl for his many helpful suggestions. Correspondence should be addressed to R. Borowsky, Psychology Department, University of Saskatchewan, 9 Campus Drive, Saskatoon, SK, S7N 5A5 Canada (e-mail: ron.borowsky @ usask.ca). during phonetic decoding. Understanding the nature of this decoding process is important to both basic and applied reading research (e.g., Borowsky et al., 1999; Coltheart, Curtis, Atkins, \& Haller, 1993; Harm \& Seidenberg, 1999; Plaut, McClelland, Seidenberg, \& Patterson, 1996). With respect to basic research, theories and models of visual word recognition (and reading development) are split into two major classes around the issue of whether an independent route is necessary to account for phonetic decoding (i.e., the single-route vs. dual-route models debate). With respect to applied reading research, a central problem concerns the developmental and acquired forms of dysfunctional phonetic decoding processing, known as phonological dyslexia. Furthermore, the form of reading instruction and remediation often referred to as phonics is concerned with enhancing phonetic decoding performance (see Adams, 1990, for a review). Thus, understanding the nature of (and developing diagnostics for) phonological lexical processing during phonetic decoding should help to advance theories and models of basic reading processes (and their development), dyslexia, and reading instruction.

A phenomenon that has been central to the study of lexical processing is the word frequency effect. Words that occur frequently in print are identified faster and/or more accurately than low-frequency words (e.g., Forster \& Chambers, 1973; Scarborough, Cortese, \& Scarborough, 1977). Word frequency effects on single-word reading performance have typically been taken as evidence that ac- 
cess of lexical (i.e., word level) representations has occurred (see Borowsky \& Masson, 1999, for a review). In models that assume that words are represented locally (i.e., separately) in memory, the word frequency effect is often taken to reflect the rate at which activation has occurred (e.g., Coltheart et al., 1993; McClelland \& Rumelhart, 1981; Morton, 1969; or rate of verification, in the case of Paap, McDonald, Schvaneveldt, \& Noel, 1987). In models in which separate word representations are not assumed, word frequency effects are manifest in the links, or connection weights, between (and often within) the representational subsystems involved (e.g., orthographic, phonological, and semantic processing subsystems; Borowsky \& Besner, 1993; Plaut et al., 1996; Zorzi, Houghton, \& Butterworth, 1998). Despite the differences between these models, word frequency effects are commonly taken as evidence that processing is sensitive to lexical structure.

Words are also identified more quickly than nonwords in both the lexical decision task and the naming task (Borowsky \& Besner, 1993; Forster \& Chambers, 1973; Stanners, Jastrzembski, \& Westbrook, 1975). These lexicality effects are also often taken as evidence that lexical activation has occurred. In both localist and distributed models of word recognition (e.g., Balota \& Chumbley, 1984; Borowsky \& Masson, 1996b), this effect has been attributed to the familiarity one gains with real words.

To account for how novel words are read, models of word identification must also deal with how one reads nonwords. Indeed, this issue has defined the two major classes of word recognition models (see Borowsky et al., 1999, for a framework that compares these two classes of models). Given that novel words and nonwords have, by definition, no direct connection from orthography to semantic representation, the emphasis here is on processing routes between orthographic representations and phonological representations that do not involve semantic mediation. Some models (e.g., Harm \& Seidenberg, 1999; Plaut et al., 1996) have postulated a single, nonsemantic route between orthographic representations and phonological representations. Thus, novel words use the same route as real words. Dual-route models (e.g., Coltheart et al., 1993; Zorzi et al., 1998) implement two nonsemantic routes between orthographic and phonological representations. One of the routes deals primarily with novel words by employing sublexical spelling-to-sound translation, whereas the other route processes familiar words by directly mapping lexical orthographic representations onto lexical phonology representations. Of particular interest in the present study was the comparison of reading orthographically novel words that either do or do not have phonological lexical representations and the conditions that yield the effects that have served as markers of phonological lexical access.

The laboratory equivalent of such orthographically novel (but phonologically familiar) words is the class of nonwords called pseudohomophones (i.e., nonwords that "sound like" real words; e.g., brane). Although these stim- uli are potentially useful for examining phonological processes in reading (in young readers as well; e.g., Goswami, Ziegler, Dalton, \& Schneider, 2001), there have been some difficulties reconciling some commonly reported effects involving pseudohomophones. The standard finding with skilled readers has been a pseudohomophone naming advantage (e.g., Herdman, LeFevre, \& Greenham, 1996, found a 39-msec advantage; McCann \& Besner, 1987, found a 35-msec advantage; Seidenberg, Petersen, MacDonald, \& Plaut, 1996, found a 16-msec advantage) accompanied by no base-word frequency effect (i.e., no significant relation between pseudohomophone naming latency and the frequency with which the base words [e.g., brain] are found in print). Most models of word recognition would be better positioned to account for the presence of a pseudohomophone advantage if it were found to occur with a significant pseudohomophone base-word frequency effect. Researchers who have reported the standard result have thus made modifications to their models to account for these apparently contradictory findings. For example, the finding of a pseudohomophone advantage without a base-word frequency effect led McCann and Besner to propose that the phonological lexical system is not itself sensitive to word frequency. Seidenberg et al. argued that, because there was no base-word frequency effect, the base-word representations are not being activated and that the advantage necessitated the implementation of a separate set of units for representing phonological articulation. However, there have recently been some unchallenged reports of a significant base-word frequency effect in pseudohomophonenaming (e.g., Borowsky \& Masson, 1996a; Grainger, Spinelli, \& Ferrand, 2000; Marmurek \& Kwantes, 1996). In the present study, we considered the conditions under which a significant base-word frequency effect is obtainable in pseudohomophone naming.

\section{Pseudohomophone Base-Word Frequency Effects}

Taft and Russell (1992) obtained an overall pseudohomophone advantage on naming latency and a significant base-word frequency effect (but only with their slower subjects). However, the possibility that subjects were treating low-frequency pseudohomophones as nonwords is a potential confound for the significant base-word frequency effect that was obtained. For example, if some lowfrequency pseudohomophones are effectively treated as nonwords by a subject, and given that nonwords tend to be named slower than pseudohomophonesin mixed lists (i.e., the pseudohomophone advantage), then an obtained baseword frequency effect could be an artifact of treating lowfrequency pseudohomophonesas nonwords. Taft and Russell attempted to ensure that their pseudohomophone stimuli would be recognized as "sounding like" real words by asking subjects in an initial experiment to decide whether or not each target stimulus sounds like a real word (i.e., a phonological lexical decision task, PLDT). We argue that this would be a more reasonable safeguard if 
done for each subject who participates in the naming task. It is also important to note that the ratio of lexical (i.e., pseudohomophone) to nonlexical (i.e., nonword) stimuli in the experiment was $2: 1$, a different ratio than the $1: 1$ ratio used by McCann and Besner (1987) and Seidenberg et al. (1996). Thus, one might argue that the presence of a base-word frequency effect may be related to the higher proportion of lexical stimuli in Taft and Russell's experiment. Perhaps the more stimuli in the experiment that can access lexical representations, the greater the probability of finding a base-word frequency effect on naming latency.

Experiments by Marmurek and Kwantes (1996) would appear to support this notion. Using a variety of different stimulus sets and ratios of lexical to nonlexical stimuli, Marmurek and Kwantes did find evidence of base-word frequency effects on pseudohomophone naming latency when the proportion of lexical stimuli was high. For example, Marmurek and Kwantes examined a condition in which subjects were presented with a block of only pseudohomophone stimuli, and they found base-word frequency effects under this "pure-block" pseudohomophone condition but not under a "mixed-block" condition (i.e., when pseudohomophones and nonwords are mixed together). Taken together with Taft and Russell's (1992) research, it appears that when using a ratio of lexical to nonlexical stimuli that is $2: 1$ or greater, base-word frequency effects on pseudohomophone naming latency begin to emerge. ${ }^{1}$ Unfortunately, Marmurek and Kwantes did not attempt to exclude poor pseudohomophone items (i.e., pseudohomophones that subjects would consider as nonwords) from their analyses but instead tried to avoid any potential confound by telling their subjects when they were about to be exposed to a pure block of pseudohomophone stimuli.

On the basis of these findings, Borowsky and Masson (1996a) suggested four criteria that may be important for demonstrating a valid base-word frequency effect on pseudohomophone naming latency: (1) Pseudohomophones and nonwords should be presented in pure blocks of trials; access to frequency sensitive representations or connections should be optimal when all of the stimuli in the experimental block have phonological lexical status and should be reduced when nonwords are mixed with the pseudohomophones. Marmurek and Kwantes (1996) examined pure blocks of pseudohomophones in their experiments but never included a pure block of nonwords. (2) Inform subjects about the nature of the stimuli that they are about to see; if subjects have any strategic control over how they process pseudohomophones and nonwords, they will be more likely to engage in lexical access during pseudohomophone naming if they know about the (intended) lexical nature of the stimuli that they are about to see (e.g., Marmurek \& Kwantes, 1996). (3) Remove any pseudohomophone stimuli (on a subject-by-subject basis) that subjects do not consider to sound like real English words; the inclusion of response latency for a lowfrequency pseudohomophone that a subject considers to be a nonword could inflate a base-word frequency effect (i.e., given that nonwords are named slower than pseudohomophones in a mixed block, such items could be contributing to an apparent base-word frequency effect). (4) The base-word stimuli themselves must be capable of eliciting a frequency effect on base-word naming latency; it should come as no surprise that there is no base-word frequency effect for pseudohomophones that are derived from base words that are not representative of the population of words that do produce a frequency effect on naming latency (McCann \& Besner, 1987). Borowsky and Masson (1999), who examined this fourth criterion using McCann and Besner's (1987), Seidenberg et al.'s (1996), and Herdman et al.'s (1996) base-word stimuli, reported that Seidenberg et al.'s base words failed to produce a significant frequency effect, thus compromising the utility of their pseudohomophone stimuli.

Following some of Borowsky and Masson's (1996a, 1999) suggestions, Grainger et al. (2000) were able to show significant base-word frequency effects in French pseudohomophone naming. Unfortunately, Grainger et al. did not check for a pseudohomophone advantage in their experiments, nor did they constrain their data analysis to items that subjects experienced as pseudohomophones.

To test our hypothesis about the critical conditions for demonstrating a base-word frequency effect on pseudohomophone naming latency, we designed Experiment 1 to examine the criteria above applied to Herdman et al.'s (1996) items, as well as a new set of pseudohomophone and nonword stimuli. Of particular interest in this experiment was whether pure block presentation of pseudohomophones and nonwords (relative to mixed presentation, the standard in the literature) would facilitate a base-word frequency effect on pseudohomophonenaming latency. The results of Experiment 1 supported this hypothesis and revealed a pseudohomophonenaming disadvantage that has never been reported in the literature. Accordingly, in Experiments 2 and 3, we examined this hypothesis and new effect with other published pseudohomophone and nonword stimuli (i.e., McCann \& Besner, 1987; Seidenberg et al., 1996).

\section{EXPERIMENT 1}

\section{Method}

\section{Subjects}

One hundred twenty University of Saskatchewan students participated in this experiment for partial credit in an introductory psychology course. An additional 25 subjects from the same population who had not participated in the pseudohomophone naming studies were assigned to name the base words for the new set of pseudohomophones. All subjects reported English as their first language and had normal or corrected-to-normal vision.

\section{Apparatus}

The experiment was conducted using an IBM-compatible computer with two monitors attached, one for the subject and the other for the experimenter. Micro Experimental Laboratories (MEL) software was used to control the timing and presentation of events and recording of the responses. A MEL serial response box was used by 
the subject to initiate each trial. A voice key connected to the serial response box was used to collect response latencies. Response latency was measured from the onset of the target on the screen to the onset of pronunciation during the naming task or the buttonpress during the phonological lexical decision task. The experimenter coded each naming response on the computer keyboard.

\section{Materials and Design}

Two sets of stimuli were presented separately to the subjects. One set of stimuli consisted of 68 pseudohomophones and 34 nonwords used by Herdman et al. (1996). The pseudohomophones ranged from 0 to 794 counts per million in base-word frequency (i.e., the frequency of occurrence in print for the words from which the pseudohomophones were derived, based on the Kučera \& Francis, 1967, corpus). Herdman et al. (1996) had originally designed 72 pseudohomophones and 34 nonwords but excluded 4 pseudohomophones and 2 nonwords from their analyses due to high error rates. These items were matched in triplets, such that, for every nonword, there was a high-frequency pseudohomophone and a low-frequency pseudohomophone. The other set of stimuli consisted of a new set of 55 pseudohomophones and 55 nonwords. The base words for the pseudohomophones were matched for word frequency, length, and initial letter to a set of regular and exception words that we have used in other studies (e.g., Borowsky, McDougall, MacKinnon, \& Hymel, 2002; Owen \& Borowsky, 2002). The nonwords were generated from the pseudohomophones by changing one letter. Four pseudohomophones and their corresponding nonwords were not included in this experiment because they also occurred in Herdman et al.'s stimulus set; thus, only 51 pseudohomophones and 51 nonwords were presented in this experiment (see the Appendix). The pseudohomophones ranged from 2 to 2,332 counts per million in base-word frequency (Kučera \& Francis, 1967). The order in which Herdman et al.'s (1996) and the new set of stimuli were presented was counterbalanced, such that half of the subjects named Herdman et al.'s (1996) stimuli followed by the new set of stimuli, and the other half of the subjects named the new set of stimuli followed by Herdman et al.'s (1996) stimuli.

The pseudohomophones were presented in pure or mixed lists. Sixty subjects were presented the pseudohomophones randomly mixed with the nonwords. In the pure-list condition, the order of stimulus presentation was counterbalanced, such that 30 subjects named a pure list of nonwords followed by the pure pseudohomophone list, and the other 30 subjects named a pure list of nonwords followed by the pure pseudohomophone list.

\section{Procedure}

When the subjects arrived at the laboratory, they were assigned to one of three conditions on the basis of an alternating sequence (i.e., mixed or pure lists, and if assigned to the pure-list condition, naming nonwords or pseudohomophones first). They were tested individually in a quiet laboratory. For the naming task, the subjects were informed as to the nature of the letter strings that they would be presented (i.e., if the letter strings were nonwords, pseudohomophones, or both) and were instructed, both orally and in writing, that they would see one letter string on each trial.

The sequence of events for the naming task was as follows: (1) A fixation cross appeared in the center of the computer screen, (2) the subject initiated the trial by pressing the middle key on the response box, (3) an interstimulus interval (ISI) of $250 \mathrm{msec}$ preceded the presentation of the stimulus, (4) a letter string appeared on the screen until the voice key was triggered, and (5) the experimenter coded each response as correct, incorrect, or spoiled (i.e., the vocal response failed to trigger the voice key, the subject stuttered, or some other noise triggered the voice key). This same procedure was followed for the subjects who named the base words.

After completing the naming task for the first set of pseudohomophones and nonwords, the subjects immediately performed a phonological lexical decision task, so as to confirm the phonological lexical status of these items for each subject. The subjects were not aware of the phonological lexical decision task before they engaged in the naming task. In the phonological lexical decision task, the subjects were instructed to decide whether each letter string could be pronounced like a word that they knew and were instructed to press the button under the dominant hand to indicate a positive response or the button under the nondominant hand to indicate a negative response. The order of stimulus presentation was individually randomized. The sequence for the phonological lexical decision task was as follows: (1) A fixation cross appeared in the center of the screen, (2) the subject initiated the trial by pressing the middle key on the response box, (3) an ISI of 250 msec preceded the presentation of the stimulus, and (4) a letter string appeared on the screen until the subject pressed one of the response buttons. The subject then named the second stimulus set, followed by the phonological lexical decision task involving these items. At the end of the experiment, the subjects were shown a graph of their performance and were debriefed as to the purpose of the experiment. The individual sessions lasted about $25 \mathrm{~min}$.

\section{Results}

The pseudohomophone advantage (whereby pseudohomophones are responded to faster and/or more accurately than nonwords) was examined using paired-sample $t$ tests in all by-subjects analyses and also in the by-items analyses with our new stimuli (i.e., each pseudohomophone was individually matched to a nonword). Independentsample $t$ tests were used for the by-items analyses of Herdman et al.'s (1996) stimuli (i.e., there was a high and a low base-word frequency pseudohomophone for every nonword, whereas the analyses on base-word frequency that follow will treat frequency as a continuous variable). In order to examine pseudohomophonebase-word frequency effects, we determined the word frequency for each item from the Kučera and Francis (1967) corpus. These frequency counts were log transformed using the following formula: $\log (10)$ word frequency $=\log (10)$ [Kučera \& Francis word frequency +1 ] (see Balota \& Chumbley, 1984; Borowsky \& Masson, 1999). This transformation on the new items resulted in a range of $\log (10)$ units from 0.477 to $3.368(M=1.815, S D=0.703)$, whereas for the Herdman et al. items, it resulted in a range of 0 to 2.900 $(M=1.470, S D=0.728)$. Two methods of regression analyses were used. First, subject-by-item regression analyses, as advocated by Lorch and Myers (1990; see also Borowsky \& Masson, 1999; LeFevre, Sadesky, \& Bisanz, 1996), were used. This method, which we will refer to as the by-subjects analysis, treats each subject's regression coefficient as a unit of analysis (i.e., performing a separate regression of correct item latency on the independent variable of word frequency for each subject, then determining whether the average regression coefficient differs from zero using a one-sample $t$ test). Only the response latencies were analyzed using this method because the errors are binary at this level of analysis (i.e., either correct or incorrect, with the vast majority correct) and thus are not normally distributed. Second, the more conventional approach of treating each item as a unit of analysis (i.e., averaging over subjects) was used for both response la- 
tency and error rate, which we will refer to as the by-items analysis.

Separate regression analyses were performed for (1) the mixed pseudohomophone-nonword condition $(n=60)$, (2) the nonword-first group $(n=30)$, and (3) the pseudohomophone-first group $(n=30)$. Regression analyses were conducted on pseudohomophone naming latency contingent on (1) correct pseudohomophonenaming accuracy and (2) correct pseudohomophonenaming for which the subjects also agreed on the lexical status of the pseudohomophone (i.e., pseudohomophones that sound like words on a subject-by-subject basis). Removing pseudohomophones that subjects may have pronounced correctly but did not classify as sounding like a real word serves to eliminate a confound between lexicality and base-word frequency, whereby low-frequency pseudohomophones that do not sound like real words to a particular subject yield inflated response latencies. In the tables that follow, we also present the standardized coefficients from each analysis involving base-word frequency. Note that the associated $p$ values are the same for unstandardized and standardized coefficients in the item analyses and that they can differ in the subject regression analyses (in which the coefficients are obtained separately for each subject, as described earlier). The results of the analyses involving standardized coefficients will be discussed only in the few cases in which the conclusions differ from the analyses of the unstandardized coefficients.

We first present the analyses on our new items, followed by analyses on the Herdman et al. (1996) items. For each set of items, analyses of the pseudohomophone naming advantage are presented first, followed by analyses of the pseudohomophone base-word frequency effects. In the analyses of response latencies, rather than rejecting a subset of observations as outliers, we computed the median to avoid influence from unusually longer response latencies.

\section{New Items}

Pseudohomophone naming advantage. To examine the data for differences between pseudohomophone and nonword median naming latencies, we conducted pairedsample $t$ tests. The median naming latencies and corresponding error rates are reported in Table 1. In the mixed pseudohomophone-nonword condition, the typical pseudohomophone naming advantage was observed by subjects $[t(59)=-4.241, p<.001]$ but was not significant by items $[t(50)=-1.505, p=.14]$. No pseudohomophone error rate advantage was observed by subjects or by items $(|t|<1$, in both cases). In the nonword-first condition, there was no pseudohomophone advantage observed for naming latencies by subjects or by items $(|t|<1$, in both cases). In the nonword-first condition a significant pseudohomophone disadvantage on error rates was revealed by subjects $[t(59)=2.177, p<.05]$. This effect was marginal by items $[t(50)=1.757, p=.085]$. In contrast, analyses of naming latencies for the pseudohomophonefirst condition revealed a pseudohomophonedisadvantage by subjects $[t(59)=3.208, p<.01]$ and by items $[t(50)=$ $5.788, p<.001]$. The significant pseudohomophone disadvantage was also reflected in the error rates by subjects $[t(59)=5.147, p<.001]$ and by items $[t(50)=2.403$, $p<.05]$

To examine the modulation of the pseudohomophone advantage effect, we compared the median response latencies of pseudohomophones in the mixed and pure pseudohomophone-first conditions, as well as the median response latencies of the nonwords in those conditions. The by-subjects analysis revealed no significant differences in response latencies when pseudohomophones and nonwords were named in mixed versus pure lists $(|t|<1.49$, $p>.145$, in all cases). However, the by-items analysis revealed that pseudohomophones were named significantly faster in the mixed condition than in the pure pseudohomophone-first condition $[t(100)=3.557, p<.01]$, whereas nonwords were named more slowly in the mixedlist condition than in the pure pseudohomophone-first condition $[t(100)=-2.241, p<.05]$.

Pseudohomophone base-word frequency effects. Table 2 summarizes the by-subjects and by-items regression analyses. Following Borowsky and Masson (1999),

Table 1

Median Naming Reaction Times (RT, in Milliseconds) and Error Rates (ER, in Percentages) for Experiment 1 as a Function of Stimulus List and Presentation Context

\begin{tabular}{|c|c|c|c|c|c|c|c|c|c|c|c|}
\hline \multirow[b]{4}{*}{ Presentation Context } & \multicolumn{11}{|c|}{ Stimulus List } \\
\hline & \multicolumn{6}{|c|}{ New Items } & \multicolumn{5}{|c|}{ Herdman et al. (1996) Items } \\
\hline & \multicolumn{3}{|c|}{ RT } & \multicolumn{3}{|c|}{ Errors } & \multicolumn{3}{|c|}{ RT } & \multicolumn{2}{|c|}{ Errors } \\
\hline & NWs & & $\mathrm{PHs}$ & NWs & & $\mathrm{PHs}$ & NWs & & $\mathrm{PHs}$ & NWs & $\mathrm{PHs}$ \\
\hline \multicolumn{12}{|l|}{ Mixed Lists } \\
\hline By Subjects & 807 & $>$ & 763 & 12.7 & & 12.4 & 719 & $>$ & 702 & 9.2 & 8.0 \\
\hline By Items & 750 & & 734 & 12.7 & & 12.4 & 673 & & 669 & 9.2 & 8.0 \\
\hline \multicolumn{12}{|l|}{ Pure Lists: NWs First } \\
\hline By Subjects & 733 & & 739 & 9.5 & & 12.2 & 684 & & 698 & 7.5 & 7.6 \\
\hline By Items & 719 & & 729 & 9.5 & $\sim$ & 12.2 & 686 & & 676 & 7.5 & 7.6 \\
\hline \multicolumn{12}{|l|}{ Pure Lists: PHs First } \\
\hline By Subjects & 790 & $<$ & 853 & 7.7 & & 11.9 & 711 & $<$ & 749 & 5.4 & $<7.8$ \\
\hline By Items & 719 & $<$ & 797 & 7.7 & $<$ & 11.9 & 656 & $<$ & 700 & 5.4 & 7.8 \\
\hline
\end{tabular}

Note-PH, pseudohomophone; NW, nonword; RT, reaction time. $<$ or $>$ indicates the direction of effect and that $p<.05 ; \sim$ indicates that $p<.10$. 
Table 2

Summary of the By-Subjects and By-Items Regression Analyses on Base-Word Frequency for Experiment 1 as a Function of Stimulus List and Presentation Context

\begin{tabular}{|c|c|c|c|}
\hline $\begin{array}{l}\text { Presentation Context } \\
\text { and Dependent Variable }\end{array}$ & Coefficient & Standardized Coefficient & $t$ \\
\hline \multicolumn{4}{|c|}{ New Items } \\
\hline \multicolumn{4}{|l|}{$\begin{array}{l}\text { Subject Regression Analyses } \\
\text { Mixed Lists }\end{array}$} \\
\hline Naming RT & -23.34 & -0.06 & $-2.53^{* * * \mathrm{~s}}$ \\
\hline Naming-PLDT RT & -10.23 & -0.03 & $-1.68 \dagger$ \\
\hline \multicolumn{4}{|l|}{ Pure Lists: NWs First } \\
\hline Naming RT & -5.44 & 0.01 & -0.43 \\
\hline Naming-PLDT RT & -1.63 & 0.01 & -0.14 \\
\hline \multicolumn{4}{|l|}{ Pure Lists: PHs First } \\
\hline Naming RT & -46.68 & -0.08 & $-3.02 *, * \mathrm{~s}$ \\
\hline Naming-PLDT RT & -45.01 & -0.07 & $-1.94 \dagger^{*} \mathrm{~s}$ \\
\hline \multicolumn{4}{|l|}{ Base words } \\
\hline Naming RT & -15.19 & -0.13 & $-3.63 * * \mathrm{~s}$ \\
\hline \multicolumn{4}{|l|}{ Item Regression Analyses } \\
\hline \multicolumn{4}{|l|}{ Mixed Lists } \\
\hline Naming RT & -14.42 & -0.14 & -0.98 \\
\hline Naming-PLDT RT & -8.14 & -0.08 & -0.57 \\
\hline Error Rates & -0.03 & -0.17 & -1.20 \\
\hline \multicolumn{4}{|l|}{ Pure Lists: NWs First } \\
\hline Naming RT & -8.25 & -0.08 & -0.53 \\
\hline Naming-PLDT RT & -17.79 & -0.16 & -1.12 \\
\hline Error Rates & 0.03 & 0.19 & 1.36 \\
\hline \multicolumn{4}{|l|}{ Pure Lists: PHs First } \\
\hline Naming RT & -41.99 & -0.29 & $-2.09 *$ \\
\hline Naming-PLDT RT & -47.86 & -0.29 & $-2.07 *$ \\
\hline Error Rates & 0.01 & 0.04 & 0.31 \\
\hline \multicolumn{4}{|l|}{ Base words } \\
\hline Naming RT & -18.09 & -0.51 & $-4.29 *$ \\
\hline Error Rates & -0.01 & -0.14 & -1.04 \\
\hline \multicolumn{4}{|c|}{ Herdman et al. (1996) Items } \\
\hline \multirow{2}{*}{\multicolumn{4}{|c|}{$\begin{array}{l}\text { Subject Regression Analyses } \\
\text { Mixed Lists }\end{array}$}} \\
\hline & & & \\
\hline Naming RT & 6.46 & 0.01 & 1.01 \\
\hline Naming-PLDT RT & 9.76 & 0.01 & 1.46 \\
\hline \multicolumn{4}{|l|}{ Pure Lists: NWs First } \\
\hline Naming RT & -0.48 & -0.01 & -0.13 \\
\hline Naming-PLDT RT & 5.17 & 0.00 & 1.15 \\
\hline \multicolumn{4}{|l|}{ Pure Lists: PHs First } \\
\hline Naming RT & -8.20 & -0.04 & -0.76 \\
\hline Naming-PLDT RT & 2.02 & -0.03 & 0.23 \\
\hline \multicolumn{4}{|l|}{ Item Regression Analyses } \\
\hline \multicolumn{4}{|l|}{ Mixed Lists } \\
\hline Naming RT & -2.92 & -0.05 & -0.38 \\
\hline Naming-PLDT RT & 0.81 & 0.01 & 0.11 \\
\hline Error Rates & 0.01 & 0.08 & 0.66 \\
\hline \multicolumn{4}{|l|}{ Pure Lists: NWs First } \\
\hline Naming RT & -1.48 & -0.02 & -0.18 \\
\hline Naming-PLDT RT & -3.81 & -0.05 & -0.44 \\
\hline Error Rates & 0.01 & 0.11 & 0.93 \\
\hline \multicolumn{4}{|l|}{ Pure Lists: PHs First } \\
\hline Naming RT & -3.97 & -0.06 & -0.46 \\
\hline Naming-PLDT RT & -12.22 & -0.12 & -0.99 \\
\hline Error Rates & 0.01 & 0.05 & 0.39 \\
\hline
\end{tabular}

Note-PH, pseudohomophone; NW, nonword; RT, reaction time; Naming-PLDT RT, naming reaction time contingent on the participant's concurring that the pseudohomophone sounded like a real word in the phonological-lexical decision task. $* p<.05$. $\quad t p<.10$. Tests of the unstandardized and standardized coefficients are identical for the item regression analyses but can differ in the subject regression analyses. In these analyses, ${ }^{* s}$ standardized coefficient, $p<.05 ;{ }^{\dagger}$ s standardized coefficient, $p<.10$. The coefficients represent milliseconds of RT/log unit increase in base-word frequency; the standardized coefficients represent $S D$ of milliseconds of RT/SD of log unit increase in base-word frequency or, equivalently, the correlation $(r)$ between RT and log base-word frequency. 
we ensured that the base words from which the pseudohomophones were derived produced a word frequency effect before determining whether the pseudohomophones would reveal similar effects. The correct naming latencies for the base words were significantly related to frequency of occurrence (see Table 2). For the mixed pseudohomophone-nonword list condition, a significant pseudohomophone base-word frequency effect was revealed on naming latencies by subjects but not by items. There was a trend for a pseudohomophone base-word frequency effect when correct naming latencies were contingent on phonological lexical decision accuracy by subjects (but not when standardized coefficients were analyzed) and not by items. No pseudohomophone base-word fre- quency effect was evident with the error rates. A subsequent set of regression analyses examined the pseudohomophone base-word frequency effect for the nonwordfirst and pseudohomophone-first conditions. For the nonword-first condition, no pseudohomophone baseword frequency effects were observed for naming latencies or error rates. For the pseudohomophone-first condition, significant pseudohomophone base-word frequency effects were revealed by subjects and by items for correct naming latencies and by items for correct naming latencies contingent on phonological lexical decision accuracy; the corresponding by-subjects analysis revealed a marginal pseudohomophone base-word frequency effect for correct naming latencies contingent on correct phonolog-
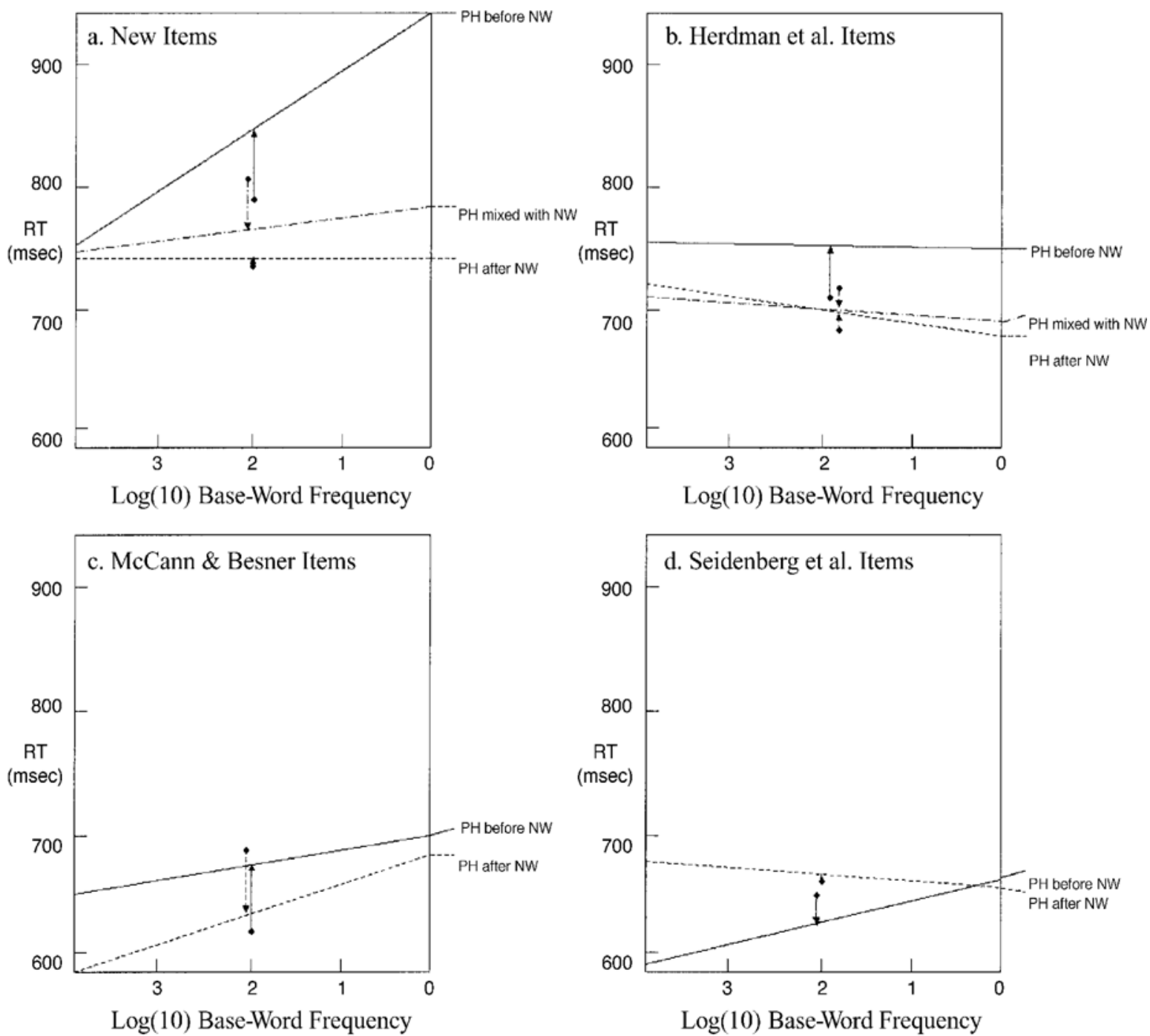

Figure 1. Summary of lexicality and base-word frequency effects involving (a) the new stimuli, (b) Herdman et al.'s (1996) stimuli, (c) McCann and Besner's (1987) stimuli, and (d) Seidenberg et al.'s (1996) stimuli. Arrow length indicates the magnitude of the lexicality effect (i.e., pseudohomophone advantage or disadvantage) by subjects. Slope represents the coefficient relating base-word frequency to pseudohomophone naming reaction time (RT; constrained by phonological-lexical decision) by subjects. 
ical lexical decision, which was significant when standardized coefficients were analyzed. A by-items regression analysis of the error rates did not reveal a significant pseudohomophone base-word frequency effect. A graphical summary of the pseudohomophone base-word frequency effects and lexicality effects (i.e., the pseudohomophone advantage/disadvantage) from the by-subjects analyses is presented in Figure 1a.

Plosivity and practice effects. Kawamoto, Kello, Jones, and Bame (1998) pointed out that words beginning with plosive consonants (i.e., obstruents and affricatives) are problematic for measuring response latency (i.e., the initiation of articulation) because there is a delay between the response latency and the generation of acoustic energy. In comparison, the acoustic energy for nonplosive consonants can be generated immediately after initiation of articulation. Thus, if two sets of stimuli to be compared differ in terms of the number of initial plosive consonants, the set with more plosives should be named more slowly. Working in opposition to this effect is the sensitivity of a voice key, in which hard onsets that are constituted by a majority of plosives may trigger the voice key over a range of intensities in which soft onsets may be less able to do so. To examine whether plosivity and/or practice had any influence on the results reported for the new pseudohomophone and nonword items, we removed 6 pseudohomophone-nonword pairs that were not matched on plosivity (e.g., feeld-teeld; $n=6$ ). The remaining 45 pairs of pseudohomophone and nonword items were identical in onset (e.g., hoest-hoert; $n=37$ ), or they had different onsets that did not change in plosivity (e.g., foart-loart; $n=$ 8 ). To determine whether practice effects contributed to or obscured any effects analyzed above, we calculated the correct median pseudohomophone and nonword naming response latencies for the first and the second half of the trials. Analyses excluding pseudohomophone-nonword pairs that did not match in plosivity and assessing effects across the first and the second half of the trials produced the same pattern of results as described above.

\section{Herdman et al. (1996) Items}

Pseudohomophone naming advantage. To examine the data for differences between pseudohomophone and nonword median naming latencies, we conducted bysubjects paired-sample $t$ tests and by-items two-sample $t$ tests. The median response latencies and corresponding error rates are reported in Table 1. In the mixed pseudohomophone-nonword condition, the typical pseudohomophone naming advantage was observed by subjects $[t(59)=-2.707, p<.01]$ but not by items $(|t|<1)$. No pseudohomophone error rate advantage was observed by subjects $(|t|<1.6$, in both cases). Analysis of list order revealed no pseudohomophoneadvantages for the nonwordfirst condition either by subjects or by items on naming latencies or error rates $(|t|<1.1$, in all cases). However, in the pseudohomophone-firstcondition, significant pseudohomophone naming disadvantages were revealed by sub- jects $[t(29)=2.855, p<.01]$ and by items $[t(100)=$ $4.114, p<.001]$. Analyses of the error rates showed a significant pseudohomophonedisad vantagein the by-subjects analysis $[t(29)=2.737, p=.01]$ but a nonsignificant pseudohomophone disadvantage in the by-items analysis $[t(100)=1.35, p=.181]$.

To examine the modulation of the pseudohomophone advantage effect, we compared the median response latencies of pseudohomophones in the mixed and pure pseudohomophone-first conditions, as well as the median response latencies of the nonwords in the mixed and pure pseudohomophone-firstconditions. The by-subjects analysis revealed no significant differences in response latencies when pseudohomophones and nonwords were named in mixed versus pure lists $(|t|<1.02$, in all cases). However, the by-items analysis revealed that pseudohomophones were named significantly faster in the mixed condition than in the pure pseudohomophone-first condition $[t(134)=3.603, p<.001]$, and there was a trend for nonwords to be named more slowly in the mixed-list condition $[t(66)=-1.672, p=.099]$.

Pseudohomophone base-word frequency effects. Table 2 summarizes the by-subjects and by-item regression analyses. For all conditions (i.e., mixed list, pure nonword-first, and pure pseudohomophone-first), no pseudohomophone base-word frequency effects were observed for naming latencies or error rates. A summary of the pseudohomophone base-word frequency effects and lexicality effects (i.e., the pseudohomophone advantage/ disadvantage) from the by-subjects analyses is presented in Figure 1b.

Plosivity and practice effects. Removing pseudohomophone-nonword triplets that did not match in plosivity would have meant removing 29 out of 34 of the triplets; thus, we restricted our analyses to an examination of potential practice effects. There was no evidence that the pseudohomophone naming lexicality effects or the pseudohomophone base-word frequency effects were influenced by practice.

\section{Discussion}

A standard pseudohomophone advantage (in the bysubjects analyses) was obtained in the mixed-list condition for both Herdman et al.'s (1996) items and our new items. However, when pseudohomophones and nonwords were presented in pure blocks, and particularly when pseudohomophones were presented first, a pseudohomophone disadvantage was obtained for both sets of stimuli. We will return to an interpretation of this novel effect on naming latency in the General Discussion section, following an examination of two other published sets of stimuli.

There were no significant pseudohomophone baseword frequency effects for Herdman et al.'s (1996) items in any of the conditions of Experiment 1, despite the fact that the base words for these stimuli have been shown to elicit a reliable frequency effect in word naming (Borowsky \& Masson, 1999). However, with our new items, even if we 
consider only effects that are significant both by subjects and by items, there was a significant base-word frequency effect for the base words themselves, as well as for the pseudohomophones derived from these base words, especially when pseudohomophones were presented first. This effect also survives the constraint of analyzing only the items that the subjects experienced as sounding like real words.

The finding that the significant pseudohomophone base-word frequency effect becomes a trend when the bysubjects analysis is constrained by PLDT accuracy suggests that the pseudohomophonebase-word frequency effect can sometimes be affected (i.e., inflated) by the inclusion of items that subjects do not consider to sound like words. Thus, having demonstrated that our experiment had sufficient power to detect a pseudohomophone baseword frequency effect with our items, and given that all subjects named both our items and Herdman et al.'s (1996) items, it would appear that Herdman et al.'s items are not sensitive to base-word frequency.

\section{EXPERIMENT 2}

In Experiment 2, we examined whether a pseudohomophone disadvantage and base-word frequency effect could be obtained with McCann and Besner's (1987) items when the pseudohomophones are presented in a pure block. Several published experiments have already replicated the pseudohomophone advantage that is found with these items in mixed-block presentation (e.g., Herdman, LeFevre, \& Greenham, 1994; Marmurek \& Kwantes, 1996).

\section{Method}

\section{Subjects}

Sixteen University of Victoria students participated in this experiment for extra credit in an introductory psychology course. All subjects had normal or corrected-to-normal vision and considered English to be their first language.

\section{Apparatus}

The apparatus was similar to that used in Experiment 1 except that the subjects used the space bar on the computer keyboard to initiate each trial, and the experimenter coded the accuracy of the subject's naming response using the MEL button box.

\section{Materials and Design}

The critical stimuli consisted of the 80 pseudohomophones and 80 nonwords used by McCann and Besner (1987). The pseudohomophones ranged from 0 to 2,439 counts per million in base-word frequency (Kučera \& Francis, 1967). The $\log (10)$ transformation on these items resulted in a range of $\log (10)$ units from 0 to $3.387(M=$ $1.597, S D=0.720$ ). In the naming task, each stimulus was seen only once, in pure blocks of pseudohomophones and nonwords, with block order counterbalanced across subjects. In the phonological lexical decision task, each stimulus was seen once again by each subject in a single, mixed block, so as to determine which stimuli the subject believed could or could not be pronounced like real words. In each task, the order of stimulus presentation was individually randomized for each subject. In addition to the critical stimuli, 20 pseudohomophones and 20 nonwords were used as practice stimuli.

\section{Procedure}

The procedure was similar to that of Experiment 1 except that the subject pressed the space bar to initiate each naming trial and that the ISI was $275 \mathrm{msec}$. The only difference in the phonological lexical decision task was that the ISI was $275 \mathrm{msec}$. All other details of the naming and phonological lexical decision tasks were the same. The individual sessions lasted approximately $20 \mathrm{~min}$.

\section{Results}

Separate regression analyses were performed for (1) the nonword-first group $(n=8)$ and (2) the pseudohomophonefirst group $(n=8)$. Regression analyses were conducted on pseudohomophone naming latency contingent on: (1) correct pseudohomophone naming accuracy and (2) correct pseudohomophonenaming for which the subjects also agreed on the lexical status of the pseudohomophone (i.e., pseudohomophones that sound like words on a subject-by-subject basis).

\section{Pseudohomophone Naming Advantage}

To examine the data for differences between pseudohomophone and nonword median naming latencies, we conducted paired-sample $t$ tests separately for the nonword-first and pseudohomophone-first conditions. The median response latencies and corresponding error rates are reported in Table 3. There was a significant pseudohomophone advantage on naming latency for the nonword-first group by subjects $[t(7)=-2.345, p=.051]$ and by items $[t(79)=-2.116, p<.05]$. A pseudo-

Table 3

Median Naming Reaction Time (RT, in Milliseconds) and Error Rates (ER, in Percentages) for Experiments 2 and 3 as a Function of Stimulus List and Presentation Context

\begin{tabular}{|c|c|c|c|c|c|c|c|c|c|}
\hline \multirow[b]{4}{*}{ Presentation Context } & \multicolumn{9}{|c|}{ Stimulus List } \\
\hline & \multicolumn{5}{|c|}{ McCann \& Besner (1987) Items } & \multicolumn{4}{|c|}{ Seidenberg et al. (1996) Items } \\
\hline & \multicolumn{3}{|c|}{ RT } & \multicolumn{2}{|c|}{ Errors } & \multicolumn{2}{|c|}{ RT } & \multicolumn{2}{|c|}{ Errors } \\
\hline & NWs & & PHs & NWs & PHs & NWs & PHs & NWs & PHs \\
\hline \multicolumn{10}{|l|}{ Pure Lists: NWs First } \\
\hline By Subjects & 691 & $>$ & 637 & 3.6 & 6.1 & 663 & 672 & 13.0 & 11.8 \\
\hline By Items & 649 & $>$ & 627 & $3.6<$ & 6.1 & 619 & $<662$ & 13.0 & 11.8 \\
\hline \multicolumn{10}{|l|}{ Pure Lists: PHs First } \\
\hline By Subjects & 617 & $\sim$ & 675 & 6.1 & 9.2 & 657 & 626 & 10.2 & 11.6 \\
\hline By Items & 613 & $<$ & 668 & $6.1<$ & 9.2 & 626 & 634 & 10.2 & 11.6 \\
\hline
\end{tabular}

Note-PH, pseudohomophone; NW, nonword; RT, reaction time. $<$ or $>$ indicates the direction of effect and that $p<.05 ; \sim$ indicates that $p<.10$. 
Table 4

Summary of the By-Subjects and By-Items Regression Analyses on Base-Word Frequency for Experiments 2 and 3 as a Function of Stimulus List and Presentation Context

\begin{tabular}{|c|c|c|c|}
\hline $\begin{array}{c}\text { Presentation Context } \\
\text { and Dependent Variable }\end{array}$ & Coefficient & Standardized Coefficient & $t$ \\
\hline \multicolumn{4}{|c|}{ Experiment 2: McCann \& Besner (1987) Items } \\
\hline \multicolumn{4}{|l|}{ Subject Regression Analyses } \\
\hline \multicolumn{4}{|l|}{ Pure Lists: NWs First } \\
\hline Naming R & -38.25 & -0.15 & $-2.09 \dagger^{*} \mathrm{~s}$ \\
\hline Naming-PLDT RT & -27.25 & -0.12 & $-2.14 \dagger^{*} \mathrm{~s}$ \\
\hline \multicolumn{4}{|l|}{ Pure Lists: PHs First } \\
\hline Naming RT & -0.46 & -0.03 & -0.78 \\
\hline Naming-PLDT RT & -12.08 & -0.05 & -1.36 \\
\hline \multicolumn{4}{|l|}{ Item Regression Analyses } \\
\hline \multicolumn{4}{|l|}{ Pure Lists: NWs First } \\
\hline Naming RT & -41.52 & -0.37 & $-3.56^{*}$ \\
\hline Naming-PLDT RT & -76.96 & -0.37 & $-3.47 *$ \\
\hline Error Rates & -0.04 & -0.23 & $-2.12 *$ \\
\hline \multicolumn{4}{|l|}{ Pure Lists: PHs First } \\
\hline Naming RT & -20.57 & -0.16 & -1.42 \\
\hline Naming-PLDT RT & -35.85 & -0.22 & $-2.01 *$ \\
\hline Error Rates & -0.02 & -0.12 & -1.09 \\
\hline \multicolumn{4}{|c|}{ Experiment 3: Seidenberg et al. (1996) Items } \\
\hline \multicolumn{4}{|l|}{ Subject Regression Analyses } \\
\hline \multicolumn{4}{|l|}{ Pure Lists: NWs First } \\
\hline Naming RT & 5.37 & -0.02 & 0.46 \\
\hline Naming-PLDT RT & 9.31 & -0.02 & 0.84 \\
\hline \multicolumn{4}{|l|}{ Pure Lists: PHs First } \\
\hline Naming RT & -15.33 & -0.05 & $-2.12 * \uparrow^{\mathrm{s}}$ \\
\hline Naming-PLDT RT & -16.59 & -0.04 & $-1.82 \dagger$ \\
\hline \multicolumn{4}{|l|}{ Item Regression Analyses } \\
\hline \multicolumn{4}{|l|}{ Pure Lists: NWs First } \\
\hline Naming RT & -2.43 & -0.03 & -0.24 \\
\hline Naming-PLDT RT & -6.65 & -0.09 & -0.67 \\
\hline Error Rates & -0.02 & -0.12 & -0.96 \\
\hline \multicolumn{4}{|l|}{ Pure Lists: PHs First } \\
\hline Naming RT & -2.56 & -0.04 & -0.29 \\
\hline Naming-PLDT RT & -6.91 & -0.07 & -0.57 \\
\hline Error Rates & 0.01 & 0.03 & 0.21 \\
\hline
\end{tabular}

Note-PH, pseudohomophone; NW, nonword; RT, reaction time; Naming-PLDT RT, naming reaction time contingent on the participant's concurring that the pseudohomophone sounded like a real word in the phonological-lexical decision task. $* p<.05 . \quad p<.10$. Tests of the unstandardized and standardized coefficients are identical for the item regression analyses but can differ in the subject regression analyses. In these analyses, ${ }^{*}$ standardized coeff icient, $p<$ $.05 ;{ }^{\dagger \mathrm{s}}$ standardized coefficient, $p<.10$. The coefficients represent milliseconds of RT/log unit increase in base-word frequency; the standardized coefficients represent $S D$ of milliseconds of $\mathrm{RT} / S D$ of log unit increase in base-word frequency or, equivalently, the correlation $(r)$ between $\mathrm{RT}$ and $\log$ base-word frequency.

homophone disadvantage was observed for the pseudohomophone-first group that was marginal by subjects $[t(7)=2.071, p=.077]$ and significant by items $[t(79)=$ $4.917, p<.001]$. No differences were observed between pseudohomophone and nonword error rates for either group of subjects in the by-subjects analyses $(t \mathrm{~s}<1.528$, $p \mathrm{~s}>.170)$, but the by-items analyses did reveal significant pseudohomophonedisadvantages between the pseudohomophone and nonword error rates for the nonword-first condition $[t(79)=2.006, p<.05]$ and the pseudohomophone-first condition $[t(79)=2.208, p<.05]$. The item analyses for the nonword-first group indicated that a speed-accuracy tradeoff had occurred. That is, this group named the pseudohomophones significantly faster than the nonwords but also at a significantly higher error rate, suggesting that the increase in speed was related to a decrease in accuracy of production. This speed-accuracy tradeoff compromised the interpretation of effects (and their direction) for both reaction time (RT) and error rate.

\section{Pseudohomophone Base-Word Frequency effects}

Table 4 summarizes the by-subjects and by-items regression analyses. In the by-subjects regression analyses, marginal pseudohomophone base-word frequency effects (which were significant when standardized coefficients were analyzed) were observed for correct naming response latencies and for correct naming response latencies contingent on the phonologicallexical decision accuracy, but only for the group of subjects who named the nonwords first. By-items regression analyses revealed sig- 
nificant pseudohomophone base-word frequency effects for correct naming response latencies and for correct naming response latencies contingent on the phonologicallexical decision accuracy for the nonword-first condition. A significant pseudohomophonebase-word frequency effect was also observed on the error rates for the nonword-first condition. In the pseudohomophone-first condition, a significant pseudohomophone base-word frequency effect was observed for correct naming response latencies contingent on the phonological lexical decision accuracy. No other by-items frequency effects were significant for the pseudohomophone-firstgroup. A summary of the pseudohomophone base-word frequency effects and lexicality effects (i.e., the pseudohomophone advantage/disadvantage) from the by-subjects analyses is presented in Figure 1c.

\section{Plosivity and Practice Effects}

To examine whether plosivity and/or practice had any influence on the results reported for the McCann and Besner (1987) pseudohomophone and nonword items, we removed pseudohomophone-nonword pairs that were not matched on plosivity (e.g., feal-beal; $n=20$ ). The remaining pairs of pseudohomophone and nonword items had different onsets that did not change in plosivity (e.g., peece-deece; $n=60$ ).

It was apparent-from removing pseudohomophonenonword pairs that did not match on plosivity and from assessing whether these same effects were stable across the first and second half of the trials- that plosivity and practice might be factors in the results just reported. In particular, the peculiar finding that the pseudohomophone naming advantage was observed for the nonword-first condition was evident only for the second half of the trials and only by subjects $[t(7)=-2.738, p<.05]$. However, the marginal pseudohomophone naming disadvantage in the pseudohomophone-first condition was evident in both the first and the second half of the trials in the bysubjects analysis $(t \mathrm{~s}>1.94, p \mathrm{~s}<.095)$ and was significant in both the first and the second half of the trials in the by-items analysis $(t>2.80, p<.01)$. For the nonwordfirst condition, there was a pseudohomophonebase-word frequency effect in the first half of the trials both by subjects and by items $(t \mathrm{~s}>-2.32, p \mathrm{~s}<.053)$, which was not present in the second half of the trials. However, for the pseudohomophone-first condition, there was a pseudohomophone base-word frequency effect in the second half of the trials but only by items $(t=-2.20, p<.05)$. For the nonword-first condition, there was no significant difference in the naming latencies of the first and the second half of the pseudohomophones. The pseudohomophones tended to be named slower in the first half of the trials $(M=660 \mathrm{msec})$ than in the second half of the trials $(M=$ $614 \mathrm{msec})(t=2.107, p=.073)$.

\section{Discussion}

Experiment 2 demonstrated that a significant pseudohomophone disadvantage and base-word frequency effect on naming latency can also be obtained with McCann and Besner's (1987) items when pseudohomophones are presented first. There was also a significant pseudohomophone advantage and base-word frequency effect on naming latency when nonwords were presented first, but these effects were compromised by a significant speed-accuracy tradeoff. In other words, the pseudohomophoneadvantage on RT was accompanied by a pseudohomophone disadvantage on error rates. Although it is not clear why our subjects traded off speed for accuracy in this condition, it is clear that there were practice effects contributing to the results obtained when nonwords were presented first. Specifically, the base-word frequency effect on RT occurred in the first half of the trials, whereas the pseudohomophone advantage on RT occurred in the second half of the trials. Furthermore, pseudohomophone naming RT decreased with practice, whereas nonword naming RT remained stable with practice. The practice-effect analyses showed that the base-word frequency effect occurred with generally slower pseudohomophone naming RTs and that the pseudohomophone naming advantage occurred with generally faster pseudohomophone naming RTs, suggestive of a scaling effect. We will return to this scaling effect account in the General Discussion section.

\section{EXPERIMENT 3}

In Experiment 3, we examined whether a pseudohomophone disadvantage and base-word frequency effect could be obtained with Seidenberg et al.'s (1996) items when the pseudohomophonesare presented in a pure block. Although it has already been shown that these pseudohomophones are derived from a set of words that do not produce a reliable word frequency effect (Borowsky \& Masson, 1999), Experiments 1 and 2 demonstrated that a pure presentation format may play a critical role in eliciting a pseudohomophone base-word frequency effect. Therefore, we examined Seidenberg et al.'s items to evaluate the sufficiency of a pure-block presentation format for eliciting the base-word frequency effect.

\section{Method}

\section{Subjects}

Thirty-four University of Saskatchewan students participated in the experiment as part of their second-year undergraduate course in psycholinguistics. They had normal or corrected-to-normal vision and considered English to be their first language.

\section{Materials and Design}

The critical stimuli consisted of the 64 pseudohomophones and 64 pronounceable nonwords used by Seidenberg et al. (1996). The pseudohomophones ranged from 0 to 9,816 counts per million in base-word frequency (Kučera \& Francis, 1967). The $\log (10)$ transformation on these items resulted in a range of $\log (10)$ units from 0 to $3.992(M=1.587, S D=0.819)$. The design, apparatus, and procedure of this experiment were similar to those of Experiment 2.

\section{Results}

Separate regression analyses were performed for (1) the nonwordfirst group $(n=17)$ and (2) the pseudohomophone-first group $(n=$ 
17). Regression analyses were conducted on pseudohomophone naming latency contingent on (1) correct pseudohomophone naming accuracy and (2) correct pseudohomophone naming for which the subjects also agreed on the lexical status of the pseudohomophone (i.e., pseudohomophones that sound like words on a subject-bysubject basis).

\section{Pseudohomophone Naming Advantage}

To examine the data for differences between pseudohomophone and nonword median naming latencies, we conducted paired-sample $t$ tests separately for the nonword-first and pseudohomophone-first conditions. The median response latencies and corresponding error rates are reported in Table 3. By-subjects analyses conducted separately for the nonword-first and pseudohomophonefirst groups revealed no significant pseudohomophone advantages for the naming response latencies or error rates (all $t \mathrm{~s}<1.397$, all $p \mathrm{~s}>.181$ ). The only significant by-items analysis revealed a pseudohomophone naming latency disadvantage for the nonword-first condition $[t(63)=4.257, p<.001]$.

\section{Pseudohomophone Base-Word Frequency Effects}

Table 4 summarizes the subject-by-item and by-item regression analyses. The by-subjects and by-items regression analyses revealed no pseudohomophone base-word frequency effects for the nonword-first condition. A significant pseudohomophone base-word frequency effect was revealed on the correct naming response latencies for the pseudohomophone-first condition by subjects (marginally significant when standardized coefficients were analyzed). A trend for a pseudohomophone base-word frequency effect by subjects (nonsignificant when standardized coefficients were analyzed) was revealed for correct naming response latencies that were contingent on phonological lexical decision accuracy. The corresponding by items regression analyses revealed no significant pseudohomophone base-word frequency effects for the pseudohomophone-first condition. A summary of the pseudohomophone base-word frequency effects and lexicality effects (i.e., the pseudohomophoneadvantage/disadvantage) from the by-subjects analyses is presented in Figure 1d.

\section{Plosivity and Practice Effects}

Because Seidenberg et al. (1996) crossed their pseudohomophone onsets and bodies to generate their list of nonwords, the number of plosive initial onsets was the same for their lists of pseudohomophones and nonwords. However, we examined the first and the second half of the trials for evidence of practice effects. There was little evidence that practice influenced the pattern of results, except for in the nonword-first condition. The pseudohomophonenaming disadvantage observed in the nonword-first condition was clearly present in the second half of the trials by items $[t(63)=2.894, p<.01]$ but not by subjects $(t=1.102$, $p=.28)$ and not at all in the first half of the trials $(t \mathrm{~s}<$ $1.406, p \mathrm{~s}>.16)$. No significant pseudohomophone base- word frequency effects were observed by subjects or by items for either the first or the second half of the trials $(|t|<0.882$, in all cases).

\section{Discussion}

The results of Experiment 3 suggest that a significant pseudohomophone disadvantage on naming latency can also be obtained with Seidenberg et al.'s (1996) items when pseudohomophones are presented separately from nonwords. However, unlike in the previous experiments, this effect occurred in the condition in which nonwords were presented first. When pseudohomophones were presented first, there was a significant base-word frequency effect on naming latency. Thus, despite the fact that these pseudohomophones were derived from words that do not produce a word frequency effect to begin with, it appears that they are capable of showing a small but significant base-word frequency effect when presented in a pure block prior to nonwords, in keeping with what has been demonstrated with our items and with McCann and Besner's (1987) items.

Given that, in the nonword-first condition, the pseudohomophone naming disadvantage appeared only in the second half of the trials, it is clear that this effect is related to practice, unlike the pseudohomophone naming disadvantage in the pseudohomophone-first conditions reported in the earlier experiments.

\section{GENERAL DISCUSSION}

Traditionally, the base-word frequency effect on pseudohomophone naming latency has been considered as a finegrained measure of phonological lexical processing, and the comparison of pseudohomophone with nonword naming latencies has been assumed to serve as a coarse measure of the same processing. As such, these effects have typically been examined together by using mixed-list experiments (e.g., Herdman et al., 1996; McCann \& Besner, 1987; Seidenberg et al., 1996; Taft \& Russell, 1992). However, these effects have not typically co-occurred with each other, contrary to predictions by most contemporary models of word recognition. The most common finding has been a null base-word frequency effect accompanied by a significant pseudohomophoneadvantage, causing researchers to modify their models of basic reading processes in order to account for these apparently discrepant effects. The present experiments demonstrated that the traditional mixed-block presentation of pseudohomophones and nonwords may be responsible for this pattern of results. When pseudohomophones are presented in a separate block, a pseudohomophone disadvantage often occurs (seen with all of the stimuli tested in the present study). Under these conditions, the base-word frequency effect most often occurred. In effect, this is the pure condition in which pseudohomophones were presented first, and a base-word frequency effect resulted for two of the stimulus sets: ours and that of McCann and Besner. The 
Seidenberg et al. stimuli elicited a frequency effect in this condition, but they produced a pseudohomophone disadvantage only when nonwords were presented firsta finding that was attributable to a practice effect.

With respect to the pseudohomophone naming effects that survived the constraint of correct performance in the PLDT and that were similar in both the items and the subjects analyses, in Experiment 1 we demonstrated a dissociation between the base-word frequency effect and the pseudohomophone advantage. ${ }^{2}$ Our new set of stimuli elicited a base-word frequency effect on pseudohomophone naming that was greatest when the pseudohomophones were presented in a separate block prior to the presentation of nonwords. This condition also elicited a pseudohomophone naming disadvantage. Herdman et al.'s (1996) stimuli also produced a pseudohomophone naming disadvantage in the pseudohomophone-first condition and a pseudohomophonenaming advantage in the mixed condition but failed to produce a significant base-word frequency effect in any of the conditions. This null effect of base-word frequency cannot be attributed to deriving the pseudohomophones from ineffective base words, since Borowsky and Masson (1999) demonstrated a significant base-word frequency effect with the base words for these items. Given that the same subjects who named our new items and demonstrated a significant pseudohomophone base-word frequency effect also named Herdman et al.'s items and failed to demonstrate any such effect, the latter stimuli must simply be less sensitive to base-word frequency. A unique characteristic of Herdman et al.'s (1996) stimuli is that half of the pseudohomophones contain illegal bodies (i.e., bodies that do not follow regular spellingto-sound translation rules). We are currently exploring whether this characteristic is a factor for the absence of a frequency effect with these stimuli.

In Experiments 2 and 3, we further explored the effects of pure-block presentation using the stimulus sets of McCann and Besner (1987) and Seidenberg et al. (1996). Both of these sets yielded significant pseudohomophone disadvantages using pure-block presentation and significant pseudohomophone base-word frequency effects in the condition in which pseudohomophones were presented first. McCann and Besner's pseudohomophone stimuli also elicited a significant pseudohomophonebaseword frequency effect when nonwords were presented first, as well as a pseudohomophone advantage, but these results were compromised by the presence of a significant speed-accuracy tradeoff between pseudohomophonesand nonwords. In this same condition, Seidenberg et al.'s stimuli produced a pseudohomophone disadvantage but no significant base-word frequency effect. However, we are reluctant to interpret null pseudohomophone base-word frequency effects with Seidenberg et al.'s stimuli, given that these stimuli were derived from words that do not elicit a significant frequency effect to begin with (Borowsky $\&$ Masson, 1999). It is interesting to note, however, that a small but significant pseudohomophone base-word fre- quency effect can be obtained with these stimuli if the pseudohomophones are presented prior to any nonwords. This suggests that the pure-block presentation format may be sufficient for producing a significant base-word frequency effect in pseudohomophone naming, even if the base words themselves do not elicit a significant word frequency effect. We now turn to a discussion of an account for these data that involves strategic processing and a general scaling effect.

\section{Strategic Regression and Scaling Effect}

A plot of the pseudohomophone base-word frequency effects and lexicality effects (i.e., the pseudohomophone advantage/disadvantage) by subjects, averaged across the four four stimulus sets, is presented in Figure 2. Viewed from this perspective, the overall data supports the notion that (1) the pseudohomophone base-word frequency effect on naming latency is seen when pseudohomophones are presented in a pure block before nonwords, and it is accompanied by relatively slow pseudohomophone naming latency and a pseudohomophone naming disadvantage, whereas (2) mixed-list presentations tend to result in $n o$ base-word frequency effect accompanied by relatively faster pseudohomophone naming latency and a pseudohomophone naming advantage. There is neither a baseword frequency effect nor a lexicality effect when pseudohomophones are presented in a pure block after nonwords, characterized by the fastest naming responses of all the conditions.

Mixed-list composition may invoke different processing strategies for pseudohomophone and nonword naming relative to pure-list presentation, which has been argued to be the case with word and nonword naming (e.g., Baluch \& Besner, 1991; Monsell, Patterson, Graham, Hughes, \& Milroy, 1992). The traditional account of the mixed-list pseudohomophone advantage, whereby the advantage reflects the benefits of phonological lexical processing when naming pseudohomophones (e.g., McCann \& Besner, 1987), seems to be a reasonable first-pass account of the present mixed-list experiments. When pseudohomophones are presented in a pure block prior to nonwords, it is plausible that subjects would often attempt phonological lexical access in that block of trials (indeed, being told that these items are designed to sound like real words must serve as an invitation to verify their phonological lexical status), thus increasing response latency relative to mixed-list presentation and allowing more opportunity for frequency-sensitive representations (or connections between lexical and semantic representations in the case of the links account of frequency effects; see Besner, 1999; Borowsky \& Besner, 1993, and McCann \& Besner, 1987), and to affect the response. In contrast, subjects would rarely bother to check representations in their phonological-lexical or semantic representations when presented with a pure block of nonword trials, thus decreasing nonword response latency, relative to mixed-list presentation. The lack of lexicality and base-word fre- 


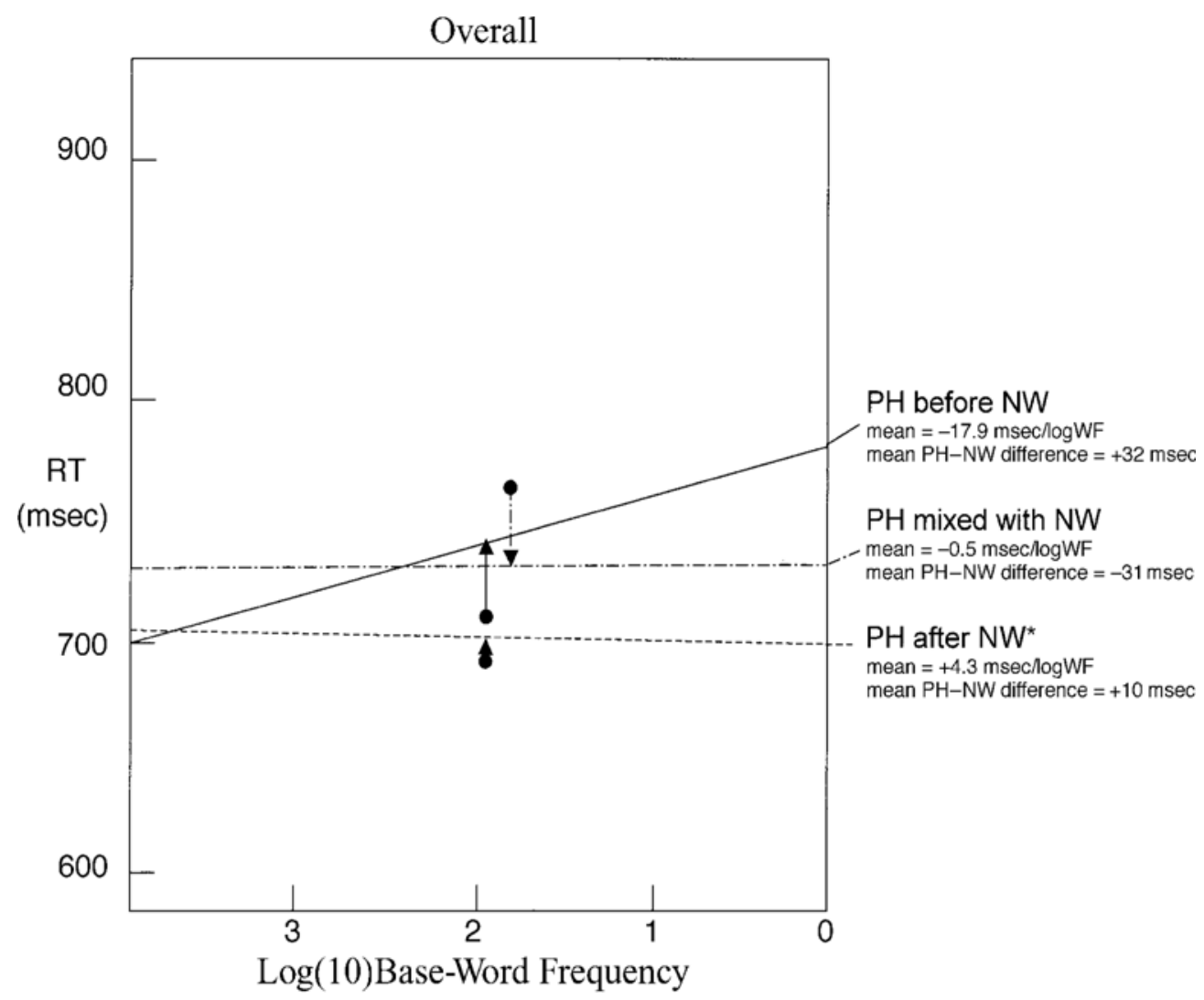

Figure 2. Summary of lexicality and base-word frequency effects averaged over the experiments. Arrow length indicates the magnitude of the average lexicality effect (i.e., pseudohomophone advantage or disadvantage)by subjects. Slope represents the average coefficient relating base-word frequency to pseudohomophone naming reaction time (RT; constrained by phonological-lexical decision) by subjects. *Excluding the Experiment 2 condition, in which a significant speed-accuracy tradeoff occurred.

quency effects when nonwords are presented prior to pseudohomophones may simply reflect a carryover effect of continuing to not verify phonological-lexical or semantic status when presented with pseudohomophones in the second block.

In mixed-list experiments, the probability of using each of these opposing strategies presumably regresses toward a moderate level for both pseudohomophones and nonwords. In other words, subjects must be less inclined to verify the pseudohomophones' phonological-lexical or semantic representations when naming them in a mixed block, given that a large proportion of the trials consisted of nonwords that would have no such representations. This decrease in intentional lexical or semantic access (i.e., a decrease in the use of verification, but not preventing lexical access per se) would serve to wash out any underlying frequency effect and also decrease pseudohomophone naming latency, relative to the condition in which pseudohomophones were presented first. In contrast, nonwords in mixed lists would be subjected to futile lexical or semantic verification more often than would those in pure lists, serving to increase nonword naming latency relative to pure-list presentation. The regression of the opposing pure-list strategies toward a moderate probability of engagement would permit the response latencies of pure-list items to be reduced in the case of pseudohomophones and increased in the case of nonwords, relative to the latencies seen with mixed-list stimuli, thereby crossing over to produce a pseudohomophone advantage (unlike an account that involves the regression of time criteria, described in the next section). Specifically, in mixed lists, the decreased explicit verification would help to speed lexical processing, with whatever verification that does occur serving to slow nonword responses more than pseudohomophoneresponses, given the well-documented effect of longer latencies to correctly respond "no" to foils resembling targets than to respond "yes" to actual targets in a variety of search/verification tasks (e.g., Coltheart, Davelaar, Jonasson, \& Besner, 1977; Treisman, 1986). The item analyses in Experiment 1, taken together with the robust pseudohomophone advantage in the literature on mixed-block presentation of pseudohomophonesand nonwords, support this account.

A sufficient account must also be capable of dealing with the null pseudohomophone base-word frequency effect that often accompanies the pseudohomophone ad- 
vantage (see Borowsky \& Masson, 1999, for a review). One way to do this is to decouple the mechanisms responsible for frequency effects and those responsible for the pseudohomophoneadvantage. For example, McCann and Besner (1987) suggested that the pseudohomophone advantage reflects the benefits of accessing phonological lexical representations, whereas the lack of frequency effect is due to not utilizing connections from the phonological lexical system to the semantic system. ${ }^{3}$ If one further assumes that intentionally utilizing these frequencysensitive links during lexical-semantic verification adds additional time to pseudohomophone naming latency in pure blocks, relative to that in mixed blocks (a reasonable assumption given that these links are activated only after one has reached the lexical level of representations) and that intentionally not using these links when nonwords are presented in pure blocks reduces nonword naming latency, relative to those presented in mixed blocks, then the present strategy account could easily be merged with McCann and Besner's account.

The scaling component of this account simply refers to any increase in base-word frequency effect that could be attributed to the general increase in pseudohomophone naming latency (and thus also the increase in size of the pseudohomophone disadvantage). A familiar example of a scaling effect is the tendency for variance to increase as a function of the mean in RT tasks. In the present experiments, as pseudohomophone naming latency slowed down, the size of the frequency effect increased, likely due to the additional time spent engaged in lexical processing and verification, which would serve to also increase the size of the pseudohomophone disadvantage. This account would predict that the pseudohomophone base-word frequency effect on naming latency should be accompanied by relatively slow pseudohomophone naming latency and a pseudohomophone naming disadvantage, whereas the lack of a base-word frequency effect should be accompanied by relatively faster pseudohomophonenaming latency and a pseudohomophone naming advantage. As a test of this scaling component, regression analyses were conducted, whereby each cell of the design from the four experiments constituted the unit of analysis (with the exception of the nonword-first condition from Experiment 2, in which a significant speed-accuracy tradeoff was observed). Specifically, considering the pseudohomophone naming data that were constrained by phonological lexical decisions, the pseudohomophonelog base-word frequency effect was regressed separately on (1) pseudohomophone naming latency and (2) the lexicality effect (with positive scores reflecting a pseudohomophoneadvantage, and negative scores reflecting a pseudohomophonedisadvantage). These analyses yielded significant coefficients in both cases: pseudohomophonenaming latency $b=-.176 \mathrm{msec} /$ $\log$ base-word frequency per millisecond of naming latency, standardized $b=-.627[t(14)=-3.008, p=$ $.009]$; lexicality effect $b=.250 \mathrm{msec} / \mathrm{log}$ base-word frequency per millisecond of lexicality effect, standardized $b=.503[t(14)=2.175, p=.047]$. In other words, the base-word frequency effect became increasingly negative
(RT decreased as frequency increased, so a larger baseword frequency effect) as a function of increasing pseudohomophone naming latency and became increasingly positive (i.e., flattening in this case) as the means tended toward a pseudohomophone naming advantage. These analyses support the scaling account of the present data.

Seidenberg et al. (1996) provided the most recent parallel distributed processing account for the pseudohomophone naming advantage, which only somewhat separates the mechanism that accounts for frequency effects from the mechanism that accounts for the pseudohomophoneadvantage. This account is implemented through the addition of articulatory units that are sensitive to the familiarity of the pronunciation of the pseudohomophones (and presumably their base-word frequency if the pseudohomophoneadvantage were sufficiently large). Thus, the pseudohomophone naming advantage is taken to represent a coarse-grained frequency effect in the articulatory system. The lack of baseword frequency effects in pseudohomophonenaming was considered to be due to a small pseudohomophone advantage (i.e., a small course-grained effect) accompanied by a lack of semantic activation (similar to the links account offered by McCann \& Besner, 1987). The present results challenge any account that considers the pseudohomophone naming advantage to reflect a coarse-grained measure of the base-word frequency effect, since these effects are clearly dissociable, depending on whether the stimuli are presented in mixed or pure blocks and depending on what order the pure blocks are presented. Seidenberg et al. claimed that strategy effects could easily be accommodated in their models (Plaut et al., 1996; Seidenberg \& McClelland, 1989); it remains to be seen whether these models can invoke strategic mechanisms that can produce a pseudohomophone disadvantage and a significant pseudohomophone baseword frequency effect under pure-block presentation conditions, in the same model that simulates a pseudohomophone advantage and diminished base-word frequency effect under a mixed-block presentation condition. Indeed, the present results provide a challenge for all classes of computational models to implement a strategy/scaling mechanism, as described earlier, to account for the double dissociation of lexicality effects (i.e., pseudohomophoneadvantage vs. disadvantage) and single dissociation of the base-word frequency effect (i.e., null vs. negative) on naming latency as a function of list context (i.e., mixed vs. pure lists).

Our position on obtaining reliable pseudohomophone base-word frequency effects when presenting pure blocks of pseudohomophones is strengthened by some of the research of Marmurek and Kwantes (1996) and Grainger et al. (2000), who also found significant effects of baseword frequency on pseudohomophone naming latency when pseudohomophones are presented in a pure block. However, their research is silent with respect to the coarsegrained measure (i.e., comparing pseudohomophone naming latency with nonword naming latency), since they never presented nonwords in pure blocks to their subjects.

Although this pseudohomophonenaming disadvantage has not been previously reported, it is interesting to note that a pseudohomophone disadvantage in orthographic 
lexical decision has been reported in the literature and that the effect has also been interpreted as being due to lexical influence. Coltheart et al. (1977) examined the effect of homophony (i.e., homophonic words are responded to faster than are matched nonhomophones) when pseudohomophones and nonwords were used as distractors in an orthographic lexical decision task (i.e., a standard lexical decision task in which subjects make their judgments based on spelling, not on sound). They showed that subjects were slower to respond that a pseudohomophonewas not a word than that a nonword was not a word (see also McCann, Besner, \& Davelaar, 1988; Seidenberg et al., 1996). The authors interpreted this pseudohomophone disadvantage as evidence that lexical phonology contributed to orthographic lexical decision performance.

\section{Can Criterion-Homogenization Account for the Present Results?}

Lupker, Brown, and Colombo (1997) advanced a criterion-homogenizationaccount of naming performance under pure versus mixed conditions. This account predicts that if pure blocks of different types of letter strings (e.g., words and nonwords) differ from each other in response latency, then latency for those types of items when presented in a mixed condition will regress toward the mean but will not change by a large enough amount to reverse the original difference. This account clearly falls short with respect to the present findings when taken together with the extant literature on mixed-list presentation of pseudohomophones and nonwords, given that the general pattern of results with pseudohomophone and nonword stimuli is a pseudohomophone advantage in mixed conditions, and this pattern crosses over to a pseudohomophone disadvantage in pure conditions. Furthermore, one thing that we have learned in the present study is that order effects can occur in the pure-block conditions (i.e., whether nonwords were presented first or last) and that pure-block differences can be masked when order is ignored. Lupker et al. did not examine order effects in their experiments.

A criterion-homogenizationaccount alone clearly would not be an adequate account of the present results. The present results do not rule out the possibility that some degree of criterion homogenization is involved, but they do rule out criterion homogenization as a sufficient account of the data. The necessity of this account cannot easily be evaluated here, given that regression toward the mean is a common characteristic of both this account and the strategic regression account described above. The idea that probability of relying on a lexical strategy regresses toward the mean does not prevent the pseudohomophone disadvantage on mean response latency in a mixed block from crossing over to yield a pseudohomophone advantage in pure blocks. Despite an interest in the area to pit strategy accounts and criteria-homogenization accounts against one another (e.g., Coltheart, 2000; Kinoshita, 2001), it seems more reasonable to consider them as not mutually exclusive.

\section{Conclusion}

The results of the present experiments suggest that the traditional mixed-list presentation method compromises the sensitivity of the experiment to measure directly the fine-grained influence of base-word frequency. The finegrained measure of assessing phonological-lexical processing via a base-word frequency effect, which has usually resulted in a null effect when examined in a mixed-list design (e.g., Herdman et al., 1996; McCann \& Besner, 1987; Seidenberg et al., 1996), occurs mainly in pure lists and most often when pseudohomophones are presented first. We contend that the course-grained measure of assessing phonological-lexical access during naming, which compares pseudohomophone naming latency with nonword naming latency, depends on presentation format (i.e., a pseudohomophone advantage in mixed lists, and a disadvantage in pure lists, particularly when pseudohomophones are presented first). This finding is contrary to the majority of models, which would naturally predict that a lexical influence should yield a processing advantage. Nonetheless, we are not advocating that pure-block presentation is "better" than mixed-block presentation, but we are stating that strategic influences differ significantly between the two types of presentation and that researchers should be aware of the difference in effects that occur as a function of presentation type.

The traditional approach to studying phonologicallexical processing, whereby pseudohomophonesand nonwords are named within a single block of mixed trials (e.g., Herdman et al., 1996; McCann \& Besner, 1987; Seidenberg et al., 1996; Experiment 1 of the present paper) has typically yielded a pseudohomophone advantage and a null pseudohomophonebase-word frequency effect. We contend that base-word frequency effects can be obtained in pseudohomophone naming if the following criteria are met: (1) Pseudohomophones are presented in pure blocks of trials, preferably before any nonword stimuli, (2) subjects are told about the nature of the stimuli in the block of trials that they are about to see, (3) pseudohomophone stimuli that subjects do not consider to "sound like" real English words are removed on a subject-by-subject basis, and (4) the base-word stimuli themselves should be capable of eliciting a frequency effect on base-word naming (Borowsky \& Masson, 1999). Given that the pseudohomophone advantage tends to reverse to a disadvantage under such conditions, this particular finding provides an interesting test for all current models of word recognition. We suggest a strategic account, whereby (1) the presentation of a pure block of pseudohomophonesmaximizes the probability that phonological lexical and semantic access will occur (and most often when pseudohomophones are presented first), (2) a pure block of nonwords minimizes this probability, and (3) a mixed block involving both types of stimuli results in a regression toward a moderate probability of invoking a lexical retrieval strategy, without preventing mean latency from crossing over to produce a pseudohomophone advantage (as opposed to the criterion-homogenization of 
Lupker et al., 1997). The co-occurrence of a base-word frequency effect with a pseudohomophone disadvantage suggests that the pseudohomophone disadvantage would better serve as a coarse-grained measure of phonological lexical/semantic access under pure-block presentation conditions, in contrast to the pseudohomophone advantage that has been observed in the mixed-block conditions here and by previous researchers. It is clear that the pseudohomophone naming advantage can no longer be assumed to simply represent a coarse-grained effect of base-word frequency (e.g., Seidenberg et al., 1996).

\section{REFERENCES}

ADAms, M. J. (1990). Beginning to read: Thinking and learning about print. Cambridge, MA: MIT Press.

Balota, D. A., \& Chumbley, J. I. (1984). Are lexical decisions a good measure of lexical access? The role of word frequency in the neglected decision stage. Journal of Experimental Psychology: Human Perception \& Performance, 10, 340-357.

BAluch, B., \& Besner, D. (1991). Visual word recognition: Evidence for strategic control of lexical and nonlexical routines in oral reading. Journal of Experimental Psychology: Learning, Memory, \& Cognition, 17, 644-652.

BESNER, D. (1999). Basic processes in reading: Multiple routines in localist and connectionist models. In R. M. Klein and P. A. McMullen (Eds.), Converging methods for understanding reading and dyslexia. Cambridge, MA: MIT Press.

BorowsKy, R, \& BESNER, D. (1993). Visual word recognition: A multistage activation model. Journal of Experimental Psychology: Learning, Memory, \& Cognition, 19, 813-840.

Borowsky, R., \& Masson, M. E. J. (1996a, November). Frequency effects in word and pseudohomophonenaming. Poster session presented at the annual meeting of the Psychonomic Society, Chicago.

Borowsky, R. \& Masson, M. E. J. (1996b). Semantic ambiguity effects in word identification. Journal of Experimental Psychology: Learning, Memory, \& Cognition, 22, 63-85.

Borowsky, R., \& Masson, M. E. J. (1999). Frequency effects and lexical access: On the interpretation of null pseudohomophonebase-word frequency effects. Journal of Experimental Psychology: Human Perception \& Performance, 25, 270-275.

Borowsky, R., McDougall, P., MacKinnon, G. E., \& Hymel, S. (2002). On the diagnosis of surface and phonologicaldyslexias: Measuring reliance on sight vocabulary and phonetic decoding during real word recognition. Manuscript submitted for publication.

Borowsky, R, OWEN, W. J., \& Fonos, N. (1999). Reading speech and hearing print: Constraining models of visual word recognition by exploring connections with speech perception. Canadian Journal of Experimental Psychology, 53, 294-305.

Coltheart, M. (2000, November). Strategic processing in reading aloud: Implications for computational models of reading. Paper presented at the 41st Annual Meeting of the Psychonomic Society, New Orleans.

Coltheart, M., Curtis, B., Atrins, P., \& Haller, M. (1993). Models of reading: Dual-route and parallel-distributed-processing approaches. Psychological Review, 100, 589-608.

Coltheart, M., Davelaar, E., Jonasson, J. T., \& Besner, D. (1977). Access to the internal lexicon. In S. Dornic (Ed.), Attention and performance VI (pp. 535-555). Hillsdale, NJ: Erlbaum.

Forster, K. I., \& Chambers, S. M. (1973). Lexical access and naming time. Journal of Verbal Learning \& Verbal Behavior, 12, 627-635.

Goswami, U., Ziegler, J. C., Dalton, L., \& Schneider, W. (2001). Pseudohomophone effects and phonological recoding procedures in reading development in English and German. Journal of Memory \& Language, 45, 648-664.

Grainger, J., Sinelli, E., \& Ferrand,L. (2000). Effects of base-word frequency and orthographic neighborhood size in pseudohomophone naming. Journal of Memory \& Language, 42, 88-102.

Harm, M. W., \& SeIDEnberg, M. S. (1999). Phonology, reading acqui- sition, and dyslexia: Insight from connectionist models. Psychological Review, 106, 491-528.

Herdman, C. M., LeFevre, J., \& Greenham, S. L. (1994). Implicating the lexicon: Base-word frequency effects in pseudohomophonenaming. Journal of Experimental Psychology: Human Perception \& Performance, 20, 575-590.

Herdman, C. M., LeFevre, J., \& Greenham, S. L. (1996). Base word frequency and pseudohomophone naming. Quarterly Journal of Experimental Psychology, 49A, 1044-1061.

Kawamoto, A. H., Kello, C. T., Jones, R. \& Bame, K. (1998). Initial phoneme versus whole word criterion to initiate pronunciation: Evidence based on response latency and initial phoneme duration. Journal of Experimental Psychology: Learning, Memory, \& Cognition, 24, 862-885.

Kinoshita, S. (2001, November). Filler type effects in naming: Control of pathways or time criterion? Paper presented at the annual meeting of the Psychonomic Society, Orlando, FL.

KUČERA, H, \& FRANCIS, W. N. (1967). Computationalanalysis of presentday American English. Providence, RI: Brown University Press.

LeFevre, J., SAdesky, G. S., \& BisAnZ, J. (1996). Selection procedures in mental addition: Reassessing the problem size effect in adults. Journal of Experimental Psychology: Learning, Memory, \& Cognition, 22, 216-230.

LoRCH, R. F., \& Myers, J. L. (1990). Regression analyses of repeated measures data in cognitive research. Journal of Experimental Psychology: Learning, Memory, \& Cognition, 16, 149-157.

LuKatela, G., \& TuRvey, M. T. (1993). Similar attentional, frequency, and associative effects for pseudohomophones and words. Journal of Experimental Psychology: Human Perception \& Performance, 19, 166-178.

LupKer, S. J., Brown, P., \& Colombo, L. (1997). Strategic control in a naming task: Changing routes or changing deadlines? Journal of Experimental Psychology: Learning, Memory, \& Cognition, 23, 570-590.

Marmurek, H. H. C., \& Kwantes, P. J. (1996). Reading words and wirds: Phonology and lexical access. Quarterly Journal of Experimental Psychology, 49A, 696-714.

McCANn, R. S., \& BESNER, D. (1987). Reading pseudohomophones: Implications for models of pronunciation and the locus of wordfrequency effects in word naming. Journal of Experimental Psychology: Human Perception \& Performance, 13, 14-24.

McCann, R. [S.], Besner, D., \& DavelaAr, E. (1988). Word recognition and identification: Do word-frequency effects reflect lexical access? Journal of Experimental Psychology: Human Perception \& Performance, 13, 693-706.

McClelland, J. L., \& Rumelhart, D. E. (1981). An interactive activation model of context effects in letter perception: Part 1. An account of basic findings. Psychological Review, 88, 375-407.

Monsell, S., Patterson, K. E., Graham, A., Hughes, C. H., \& MilROY, R (1992). Lexical and sublexical translation of spelling to sound: Strategic anticipation of lexical status. Journal of Experimental Psychology: Learning, Memory, \& Cognition, 18, 452-467.

Morton, J. (1969). Interaction of information in word recognition. Psychological Review, 76, 165-178.

OwEN, W. J., \& BoROWSKY, R. (2002). Evaluating the relationship between phonetic decoding and sight vocabulary: Evidence for single or dual routes? Manuscript under review.

PaAp, K. R., McDonald, J. E., Schvaneveldt, R. W., \& Noel, R. W. (1987). Frequency and pronounceability in visually presented naming and lexical decision tasks. In M. Coltheart (Ed.), Attention and performance XII: The psychology of reading (pp. 221-243). Hillsdale, NJ: Erlbaum.

Plaut, D. C., McClelland, J. L., Seidenberg, M. S., \& Patterson, K. E (1996). Understanding normal and impaired word reading: Computational principles in quasi-regular domains. Psychological Review, 103, 56-115

Scarborough, D. L., Cortese, C., \& Scarborough, H. L. (1977). Frequency and repetition effects in lexical memory. Journal of Experimental Psychology: Human Perception \& Performance, 3, 1-17. SeidenberG, M., \& McClelland, J. (1989). A distributed developmental model of word recognition and naming. Psychological Review, 96, 523-568. 
Seidenberg, M. S., Petersen, A., MacDonald, M. C., \& Plaut, D. C. (1996). Pseudohomophone effects and models of word recognition. Journal of Experimental Psychology: Learning, Memory, \& Cognition, 22, 48-62.

Stanners, R. F., Jastrzembski, J. E., \& Westbrook, A. (1975). Frequency and visual quality in a word-nonword classification task. Journal of Verbal Learning \& Verbal Behavior, 14, 259-264.

TAFT, M., \& Russell, B. (1992). Pseudohomophone naming and the word frequency effect. Quarterly Journal of Experimental Psychology, 45A, 51-71.

Treisman, A. (1986). Features and objects in visual processing. Scientific American, 254, 114-125.

Zorzi, M., Houghton, G., \& Butterworth, B. (1998). Two routes or one in reading aloud? A connectionist dual-process model. Journal of Experimental Psychology: Human Perception \& Performance, 24, 1131-1161.

\section{NOTES}

1. Herdman et al. (1996) used 2:1 ratio (with half of the pseudohomophones containing legal bodies, and half containing illegal bodies) but did not obtain a significant base-word frequency effect. Borowsky and Masson (1999) pointed out that a speed-accuracy tradeoff appears to compromise Herdman et al.'s results. Also, some mention should be made of the studies that report a reverse base-word frequency effect on pseudohomophonenaming latency (e.g., Herdman et al., 1994; Lukatela
$\&$ Turvey, 1993). It turns out that these studies report reverse frequency effects only in analyses that treat subjects as the random variable, but not in analyses that treat items as the random variable. This means that as few as one or two "strange" items can be responsible for the significant "reverse" effect (e.g., a high base-word frequency pseudohomophone that is named very slowly, and/or a low base-word frequency pseudohomophone that is named very quickly), and thus it is of utmost importance that by-items analyses be conducted to assess this possibility. We also direct the reader to a more detailed criticism of the Herdman et al. study in Seidenberg et al. (1996).

2. In keeping with our constrained analyses on base-word frequency effects, we conducted a set of analyses on the pseudohomophone advantages/disadvantages that were restricted to items for which the lexical status was confirmed by each subject in the PLDT. The constrained analyses were mostly consistent with the unconstrained analyses, and the means for the tests that differed between unconstrained and constrained analyses remained in the same direction. The two tests that differed were new items, pure blocks, nonword-first condition by items $[t(50)=$ $2.186, p<.05]$, and McCann and Besner's (1987) items, nonword-first condition by items $[t(79)=-0.582, p=.562]$.

3. See also the study of Borowsky and Besner (1993), in which links between phonological and orthographic lexical systems were also considered to be frequency-sensitive; thus, checking a pseudohomophone target against one's orthographic lexical system may produce a similar effect as checking one's semantic system.

\begin{tabular}{|c|c|c|}
\hline \multicolumn{3}{|c|}{$\begin{array}{c}\text { APPENDIX } \\
\text { Base Words, Pseudohomophones, and Nonwords } \\
\text { Used in Experiment } 1 \\
\end{array}$} \\
\hline Base Word & Pseudohomophone & Nonword \\
\hline host & hoest & hoert \\
\hline when & wehn & sehn \\
\hline state & stait & shait \\
\hline turn & terhn & gerhn \\
\hline down & doun & loun \\
\hline miles & mylz & mydz \\
\hline mind & mynd & nynd \\
\hline out & owt & ost \\
\hline white & whyt & ghyt \\
\hline held & helled & helked \\
\hline drive & dryv & dryn \\
\hline least & leest & leext \\
\hline game & gaim & gair \\
\hline wife & wyfe & vyfe \\
\hline fine & fyne & fyce \\
\hline hot & hawt & hant \\
\hline walk & wawk & wawf \\
\hline boat & bote & boke \\
\hline golf & gawlf & gawlt \\
\hline late & layt & payt \\
\hline guide & gyde & gfe \\
\hline field & feeld & teeld \\
\hline floor & flore & flove \\
\hline wise & wyz & vyz \\
\hline woke & woak & woaf \\
\hline hope & hoap & hoaj \\
\hline born & boarn & boarm \\
\hline pride & pryd & pryf \\
\hline spot & spawt & spawl \\
\hline tune & toon & toov \\
\hline nice & nyse & nyre \\
\hline clean & cleen & cleem \\
\hline
\end{tabular}


APPENDIX (Continued)

\begin{tabular}{lll}
\hline Base Word & Pseudohomophone & Nonword \\
\hline fort & foart & loart \\
hold & hoald & hoalt \\
more & mohr & nohr \\
breeze & breaz & brean \\
brave & braiv & brair \\
bone & boan & boam \\
burn & bern & berv \\
theme & theem & theen \\
flash & phlash & phlast \\
tool & tule & tufe \\
swiss & swhis & swhin \\
edge & ehj & ehp \\
swore & swoar & swoam \\
colt & coalt & coaft \\
drawer & drore & drose \\
stroll & stroal & stroat \\
dot & dawt & davt \\
hedge & hedj & bedj \\
soak & soke & sofe \\
seeks & seaks & seafs \\
moths & mawths & mamths \\
class & klass & plass \\
trump & truhmp & kruhmp \\
\hline & &
\end{tabular}

(Manuscript received January 9, 2001;

revision accepted for publication March 12, 2002.) 